\title{
Changes in Maternal Body Mass Index, Weight Gain and Outcome of Singleton Pregnancies from 2000 to 2015
}

A Population-based Retrospective Cohort Study in Hesse/Germany

Veränderungen des mütterlichen BMI, Gewichtszunahme und Schwangerschaftsoutcome bei Einlingsschwangerschaften von 2000 bis 2015

\author{
Eine retrospektive bevölkerungsbezogene Kohortenstudie in Hessen/Deutschland
}

\section{(ㄷ)(i) (로 $\ominus$}

Authors

Kathrin Noever ${ }^{1,2}$, Julia Schubert ${ }^{1,2}$, Edith Reuschel ${ }^{3}$, Nina Timmesfeld ${ }^{4}$, Birgit Arabin ${ }^{1,5}$

\section{Affiliations}

1 Clara Angela Foundation, Witten und Berlin, Germany

2 Center for Mother \& Child, Philipps University Marburg, Marburg, Germany

3 Department of Obstetrics and Gynecology of the University of Regensburg, Hospital of the Barmherzige Brueder, Klinik St. Hedwig, Regensburg, Germany

4 Department for Medical Computer Science, Biometry and Epidemiology, Ruhr-Universität Bochum, Bochum, Germany

5 Department of Obstetrics, Charité, Humboldt University Berlin, Berlin, Germany

\section{Key words}

body mass index (BMI), gestational weight gain, overweight, obesity

Schlüsselwörter

Body-Mass-Index (BMI), Gewichtszunahme in der

Schwangerschaft, Übergewicht, Adipositas

received $\quad 3.10 .2019$

revised 26.1.2020

accepted 29.1.2020

Bibliography

DOI https://doi.org/10.1055/a-1110-0859

published online 16.4.2020 | Geburtsh Frauenheilk 2020; 80: 508-517 @ Georg Thieme Verlag KG Stuttgart · New York | ISSN 0016-5751

Correspondence

Kathrin Noever

Center for Mother \& Child, Philipps University of Marburg

Baldingerstraße 1, 35033 Marburg, Germany

K.Noever@t-online.de
ABSTRACT

Introduction Maternal obesity and excessive gestational weight gain (GWG) affect the outcomes of women and their offspring. Our aim was to evaluate population-based data from Germany.

Material and Methods Data from 583633/791514 motherchild pairs obtained from the perinatal database in Hesse for the period from 2000 to 2015 were used after excluding incomplete or non-plausible datasets. Early-stage pregnancy maternal body mass index (BMI) and GWG were evaluated. Significant outcome changes were calculated using linear or logistic regression models.

Results The mean maternal age increased from 29.9 to 31.28 years; GWG increased from 445.1 to $457.2 \mathrm{~g} /$ week $(p<0.01)$. Similarly, rates for both overweight and obesity rose from 31.5 to $37.5 \%(p<0.001)$. Cesarean section rates rose from 22.8 to $33.2 \%(p<0.001)$ and rates of postpartum hemorrhage increased from 0.6 to $1 \%(p<0.001)$. There was no significant change in the rates for stillbirth or perinatal mortality ( $\mathrm{p}=0.92$ and $\mathrm{p}=0.53$ respectively), but there was an increase in the rates of admissions to neonatal intensive care units from 7.8 to $9.5 \%(p<0.0001)$. The percentage of newborns with an Apgar score of $<7$ at 5 minutes increased from 1 to $1.1 \%(p<0.01)$ and the rate of neonates with an umbilical artery $\mathrm{pH}$ of $<7.1$ rose from 1.7 to $2.4 \%(\mathrm{p}<0.01)$.

Conclusions In just 15 years, pre-pregnancy BMI and GWG rates of women with singleton pregnancies have increased, and this increase has been accompanied by a significant rise in the rate of cesarean sections and a significant worsening of short-term maternal and neonatal outcomes. It is time to discuss the risks and the short-term and more worrying longterm consequences for mothers and their offspring and the future impact on our healthcare system. 


\section{ZUSAMMENFASSUNG}

Einleitung Mütterliches Übergewicht und übermäßige Gewichtszunahme in der Schwangerschaft (GWG) wirken sich auf das Outcome von Mutter und Kind aus. Ziel unserer Untersuchung war es, bevölkerungsbezogene Daten aus Deutschland dahingehend auf Veränderungen zu untersuchen.

Material und Methoden Die Daten von 583633/791514 Mutter-Kind-Paaren aus der perinatalen Datenbank des Bundeslandes Hessen für die Periode von 2000 bis 2015 wurden für die Untersuchung herangezogen. Unvollständige und nicht plausible Datensätze wurden vor der Evaluierung ausgeschlossen. Der mütterliche Body-Mass-Index (BMI) in der Frühschwangerschaft und die Gewichtszunahme in der Schwangerschaft wurden evaluiert. Signifikante Änderungen wurden mithilfe linearer bzw. logistischer Regressionsmodelle berechnet.

Ergebnisse Das mittlere mütterliche Alter nahm von 29,9 auf 31,28 Jahre zu; die mittlere Gewichtszunahme in der Schwangerschaft nahm ebenfalls von 445,1 auf 457,2 g/Woche zu $(p<0,01)$. Entsprechend nahm auch die Übergewichts- und Adipositasrate zu und stieg von 31,5 auf 37,5\% ( $<<0,001)$.
Die Sectiorate stieg von 22,8 auf 33,2\% ( $p<0,001)$, und die Rate postpartaler Blutungen nahm von 0,6 auf $1 \%$ zu $(p<0,001)$. Es gab keine signifikanten Änderungen bei der Totgeburtenrate bzw. der perinatalen Sterblichkeit ( $p=0,92$ resp. $p=0,53$ ), aber die Rate der Aufnahmen in einer neonatalen Intensivstation stieg von 7,8 auf 9,5\% ( $p<0,0001)$. Der Prozentsatz an Neugeborenen mit einer Apgar-Zahl von $<7$ nach 5 Minuten nahm von 1 auf $1,1 \%$ zu $(p<0,01)$, und die Rate der Neugeborenen mit einem Nabelschnur-pH-Wert von weniger als 7,1 stieg von 1,7 auf $2,4 \%(p<0,01)$.

Schlussfolgerungen Innerhalb von nur 15 Jahren sind die Vor-Schwangerschafts-BMI- und GWG-Raten bei Frauen mit Einlingsschwangerschaften angestiegen. Dieser Anstieg ging mit einer signifikanten Erhöhung der Sectiorate und einer signifikanten Verschlechterung der kurzfristigen mütterlichen und neonatalen Outcomes einher. Es ist Zeit, die Risiken und die kurzfristigen und noch bedenklicheren langfristigen Konsequenzen für Mutter und Kind sowie die Auswirkungen auf unser künftiges Gesundheitssystem zu diskutieren.

\section{Introduction}

There has been a global shift from under- to overnutrition [1]. The WHO reported that in 2016 more than 1.9 billion adults aged $>18$ years met the criteria for being overweight (body mass index [BMI] of $25 \mathrm{~kg} / \mathrm{m}^{2}$ and above) or obese (BMI $\geq 30 \mathrm{~kg} / \mathrm{m}^{2}$ ) [2]. Similarly, women of childbearing age have also shown rising rates of overweight and obesity. Both overweight and obesity increase the risk of gestational diabetes (GDM) and hypertensive disorders of pregnancy (HDP) and, what is even worse, have irreversible long-term effects on mothers and their offspring [3].

Already in 2014, a study published in this journal showed that obesity and excessive weight gain (EGWG) in pregnancy have a serious impact on maternal, fetal and neonatal outcomes and are associated with weight gain in women following childbirth and long-term cardiovascular and metabolic risk factors [4]. Similarly, the long-term risks for offspring are early cardiovascular disease, metabolic syndrome and decreased life expectancy as adults, even after correction by lifestyle changes later in life [5]. The pathophysiological mechanisms of fetal programming have also been discussed in this journal [6]. Since lifestyle changes to control maternal weight before, during and after pregnancy must be done by the pregnant women themselves, obstetricians should inform their patients about the consequences and help improve their health literacy [7]. Additionally, midwives could also address the issue by stressing the importance of close cooperation during the monitoring period $[8,9]$. Sadly, this important public health problem has not generated the level of concern it warrants among healthcare specialists, policy makers or individual members in our society.

In Germany, there are still no clinical guidelines on how to deal with maternal obesity before, during or after pregnancy. Even if such German guidelines were to be completed and published, ob- stetric guidelines alone will not necessarily change the behavior of healthcare providers or their patients as noted elsewhere [7]. In the US, both an ACOG Committee Opinion [10] and a Practice Bulletin [11] underlined the importance of proper information about evidence-based criteria and BMI-adapted weight gain recommendations during pregnancy [12]. Nevertheless, obesity among USwomen of childbearing age has increased to such an extent that now $48 \%$ of all US pregnant women gain more weight than recommended [13].

In order to demonstrate the necessity for change to policy makers and parents-to-be, we therefore decided to analyze the course of overweight, obesity and weight gain during pregnancy and the associated immediate risks and outcomes in a large regional cohort, with the data obtained from a German Perinatal Database (HESSEN) for the period from 2000 to 2015.

\section{Materials and Methods}

\section{Study group}

The office for quality management in Hesse (a federal state in Germany with 6176172 inhabitants in 2015 [14]) approved our application for this large project and allowed us to access their perinatal database for the period from 2000 to 2015 . This database records all deliveries in Hesse except for home births. Data relating to patients and centers are anonymized. Since there is no direct quality control of the data when it is entered in the database, an extensive plausibility control had to be performed. Nonplausible data were registered as "missing data”.

Criteria for inclusion in the final analysis were: singleton pregnancy, an initial clinical and ultrasound examination before 14 weeks of gestation, a gestational age at delivery of at least 24 weeks, a maternal height equal to or higher than $120 \mathrm{~cm}$, and 


\begin{tabular}{|c|c|c|}
\hline \multirow[b]{2}{*}{ Excluded: } & \multicolumn{2}{|c|}{$\begin{array}{c}\text { All cases registered } \\
\text { between } 2000 \text { and 2015: } \\
n=820174\end{array}$} \\
\hline & $n=236541$ & \\
\hline Multiple pregnancy: & $n=28660$ & \\
\hline $\begin{array}{l}\text { First clinical + ultrasound } \\
\text { examination after } \\
14 \text { weeks of gestation: }\end{array}$ & $n=146841$ & \\
\hline $\begin{array}{l}\text { Maternal height not } \\
\text { available or < } 120 \mathrm{~cm} \text { : }\end{array}$ & $\mathrm{n}=28839$ & \\
\hline $\begin{array}{l}\text { Gestational age at } \\
\text { delivery }<24 \text { weeks: }\end{array}$ & $\mathrm{n}=981$ & \\
\hline \multirow[t]{2}{*}{$\begin{array}{l}\text { Maternal weight not } \\
\text { available: }\end{array}$} & $\mathrm{n}=31220$ & \\
\hline & \multicolumn{2}{|c|}{$\begin{array}{l}\text { Included: } \\
\mathrm{n}=583633\end{array}$} \\
\hline
\end{tabular}

- Fig. 1 Flow chart showing criteria for inclusion in the study.

availability of all data relating to maternal weight at the start of pregnancy and at delivery ( $\triangleright$ Fig. 1). The final study cohort therefore consisted only of 583633 of the original 791514 motherchild pairs (73.7\%) ( Table 1$)$.

\section{Outcome criteria}

Maternal age at delivery was calculated as the difference between the mother's year of birth and the year of delivery. BMI was calculated as $\mathrm{kg} / \mathrm{m}^{2}$ and classified using the WHO criteria: BMI $<18.5 \mathrm{~kg} / \mathrm{m}^{2}$ : "underweight"; BMI $18.5-24.9 \mathrm{~kg} / \mathrm{m}^{2}$ : "normal weight”; BMI 25.0-29.9 kg/m²: “overweight”; BMl $\geq 30 \mathrm{~kg} / \mathrm{m}^{2}$ : "obesity" [15]. The (weekly) maternal gestational weight gain (GWG) was calculated as the difference between maternal weight at the first examination and weight at delivery, respectively, divided by the duration of this interval in weeks. Based on the IOM guidelines, women were classified as GWG below, GWG within and GWG above the optimal range.

The birth weight (BW) was categorized into groups of $500 \mathrm{~g}$ ranging from $<1500 \mathrm{~g}$ to $\geq 4000 \mathrm{~g}$. Similarly, gestational age at birth was categorized from $<28$ weeks up to $\geq 37$ weeks of gestation.

The incidence of HDP was calculated indirectly from recorded clinical findings and defined using the criteria of the International Society for the Study of Hypertension in Pregnancy (ISSHP) [16].

\section{Statistical analysis}

Mean values per year were calculated for all numerical outcomes, and significant differences were analyzed during the observation period using a linear regression model. Rates (\%) for categorical outcomes were analyzed using logistic regression models. The
- Table 1 Characteristics of the study group. $n=583633 / 791514$ singleton pregnancies delivered between 2000 and 2015 in Hesse, Germany; 207881 pregnancies were excluded after carrying out a plausibility control.

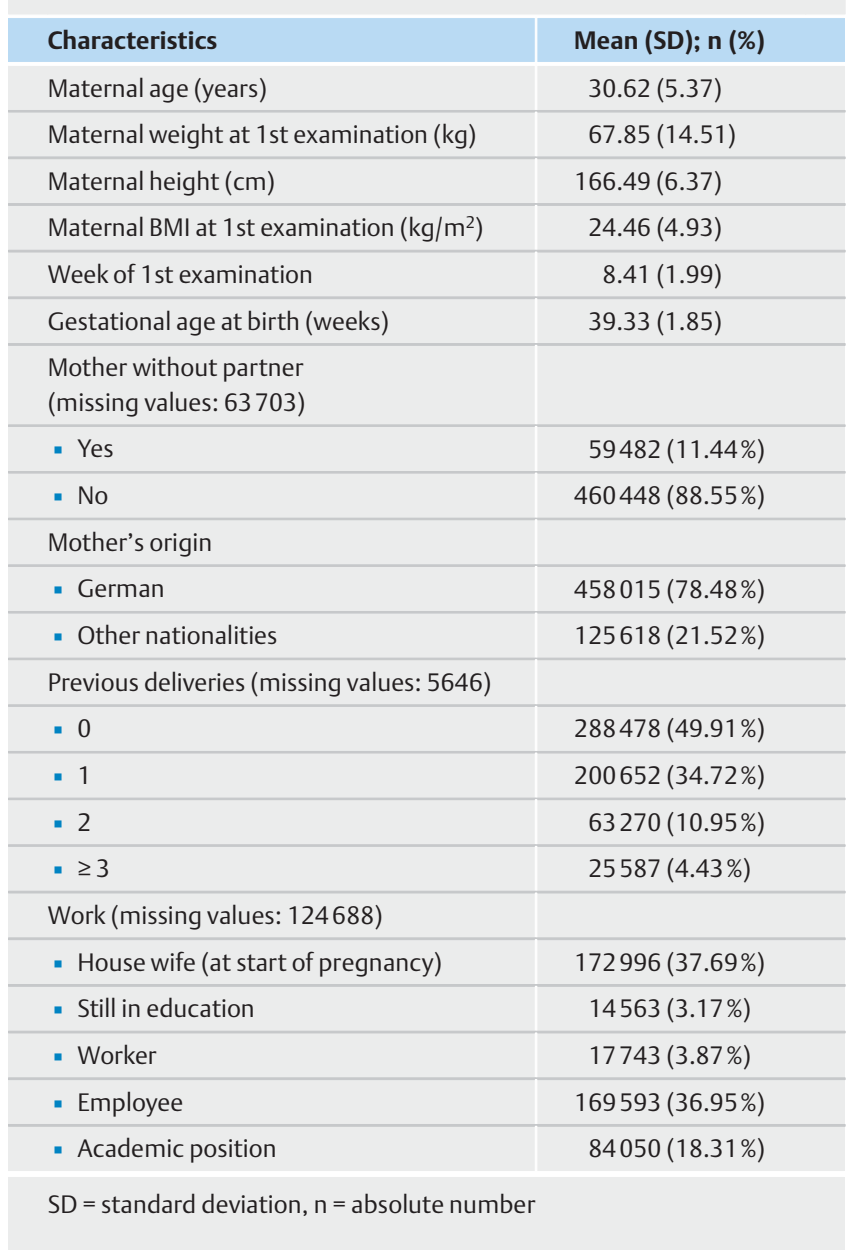

programs $R$ for Windows 3.5.1, R Studio (Version 1.1.456) and Excel 2013 were used for statistical evaluation.

\section{Results}

\section{Characteristics of the study group}

Between 2000 and 2015, a total of 820174 deliveries were registered in Hessen, of which 791514 were singleton pregnancies (96.5\%). After applying the inclusion criteria (• Fig. 1) 583633 cases remained for the final analysis; the characteristics of this final study group are shown in $>$ Table 1 . Around $50 \%$ of the women were primiparous, $21.5 \%$ did not originate from Germany, and around $37 \%$ of pregnant women did not work.

\section{Changes in BMI, GWG, and outcomes between 2000 and 2015}

The mean BMI of all women between 2000 and 2015 at their first examination was $24.46 \mathrm{~kg} / \mathrm{m}^{2}$, meaning that it was within the normal upper range. Mean maternal age increased from 29.9 to 

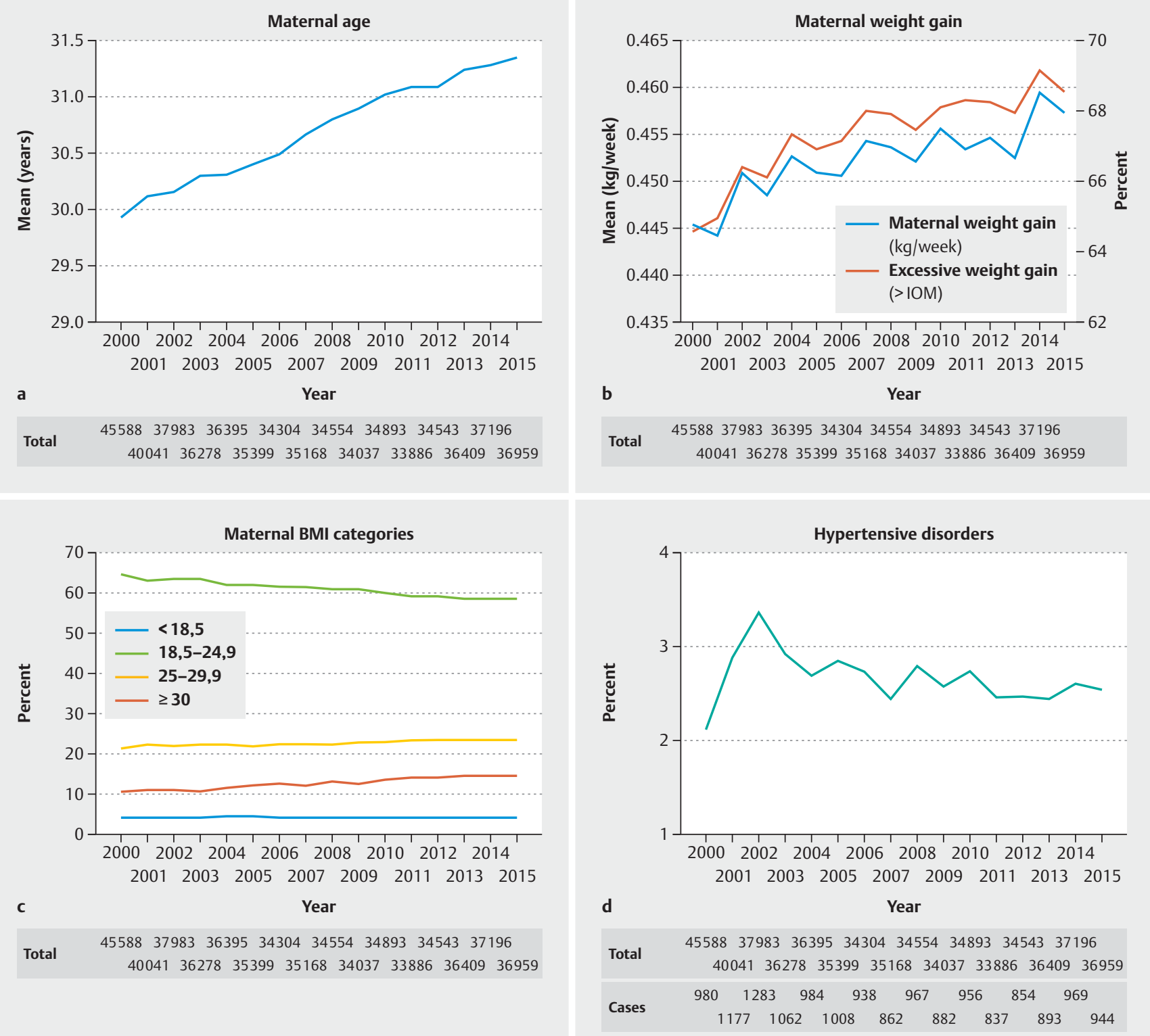

- Fig. 2 Course of maternal outcomes between 2000 and 2015. Total $=$ total singleton deliveries $(n=583633)$, cases = absolute incidence of specific outcome, $+=$ positive correlation, $-=$ negative correlation. Statistical analysis was carried out using linear (a, b) or logistic (c, d) regression. a Mean maternal age (years): $\mathrm{p}=0.001(+)$. b Mean maternal weight gain/gestational week $(\mathrm{kg} /$ week): $\mathrm{p}<0.0001(+)$ : c Maternal BMI categories (\%) at 1st examination (<14 weeks of gestation): underweight: $n=22632, p=0.014(-)$; normal weight: $n=358101, p<0.001(-)$; overweight: $n=130937, p<0.001(+)$; obese: $n=71963, p<0.001(+)$. $d$ Hypertensive disorders of pregnancy $(\%): n=15596, p<0.001(-)$.

31.28 years ( $\vee$ Fig. 2 a) $(\mathrm{p}<0.001)$, with the age of primiparous women rising from 28.48 to 30.00 years $(p<0.001)$. There were no records for $63703 / 583633$ women showing whether the women were living with a defined partner or alone; of the remaining 519930 women, 59482 (11.5\%) were single ( $>$ Table 1).

The mean maternal height $(166.49 \mathrm{~cm})$ did not change significantly during the observation period ( $p=0.17$ ), but the mean maternal weight at the first examination rose from $66.79 \mathrm{~kg}$ in 2000 to $68.72 \mathrm{~kg}$ in 2015 ( $p<0.0001$ ). Accordingly, there was also a significant increase in mean maternal BMI in early pregnancy from
$24.10 \mathrm{~kg} / \mathrm{m}^{2}$ in 2000 to $24.80 \mathrm{~kg} / \mathrm{m}^{2}$ in 2015 ( $\left.\mathrm{p}<0.0001\right)$. The categories for the BMI classification using the WHO definition are

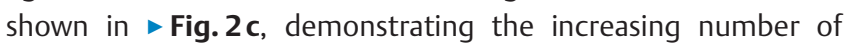
women with overweight or obesity at the first examination $(p<0.001)$ and the decreasing rates of underweight $(p=0.014)$ and normal-weight women $(p<0.001)$.

The mean weekly GWG between 2000 and 2015 rose from $445.1 \mathrm{~g} /$ week to $457.2 \mathrm{~g} /$ week ( $>$ Fig. $\mathbf{2}$ b, p < 0.001). The rate of women gaining weight within the range recommended by the IOM decreased from $23.5 \%$ in 2000 to $20.23 \%$ in 2015 , while the 


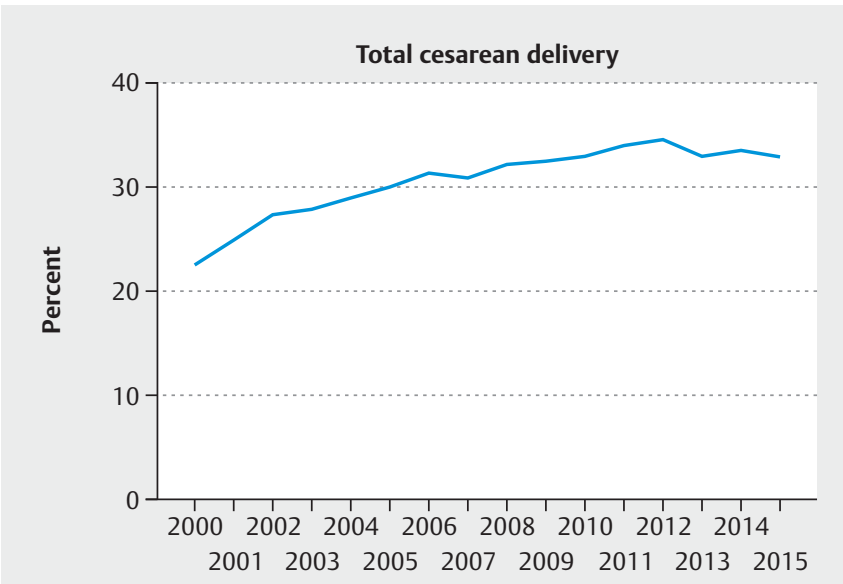

a
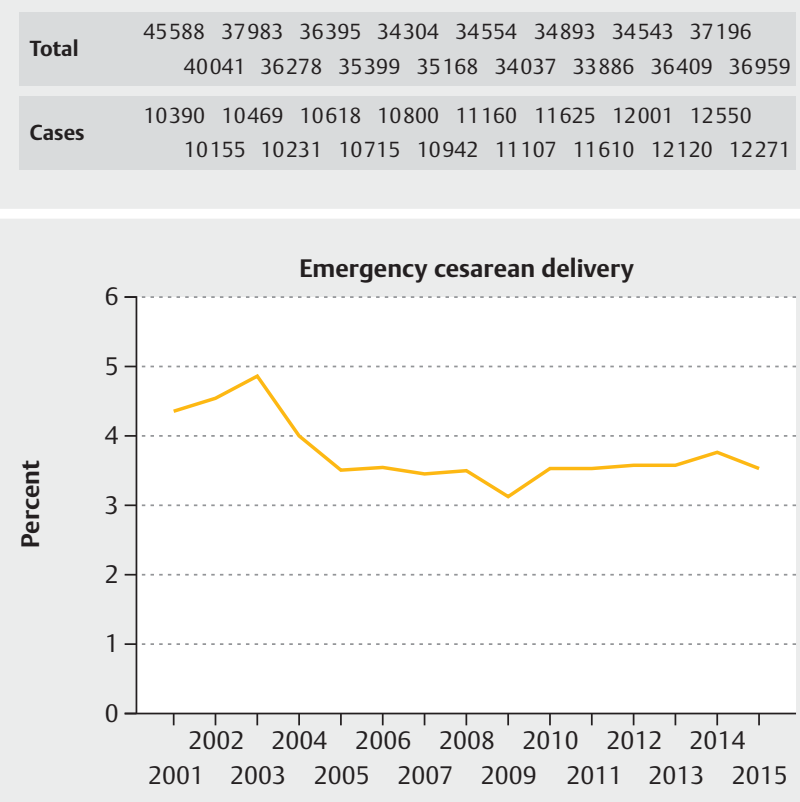

c

\section{Year}

Total

$\begin{array}{lllllll}10906 & 10617 & 10800 & 11160 & 11625 & 12001 & 12550\end{array}$ $\begin{array}{llllllll}11413 & 10231 & 10715 & 10942 & 11107 & 11610 & 12120 & 12271\end{array}$

\begin{tabular}{lllllllllllll} 
& Cases & \multicolumn{1}{c}{497} & 423 & 384 & 393 & 413 & 428 & 473 \\
& 500 & 497 & 377 & 380 & 349 & 411 & 435 & 437
\end{tabular}

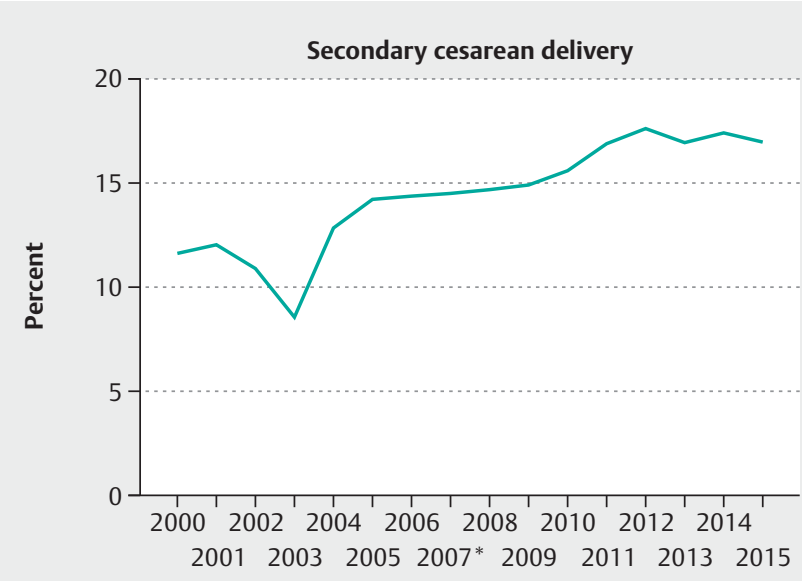

b

Year

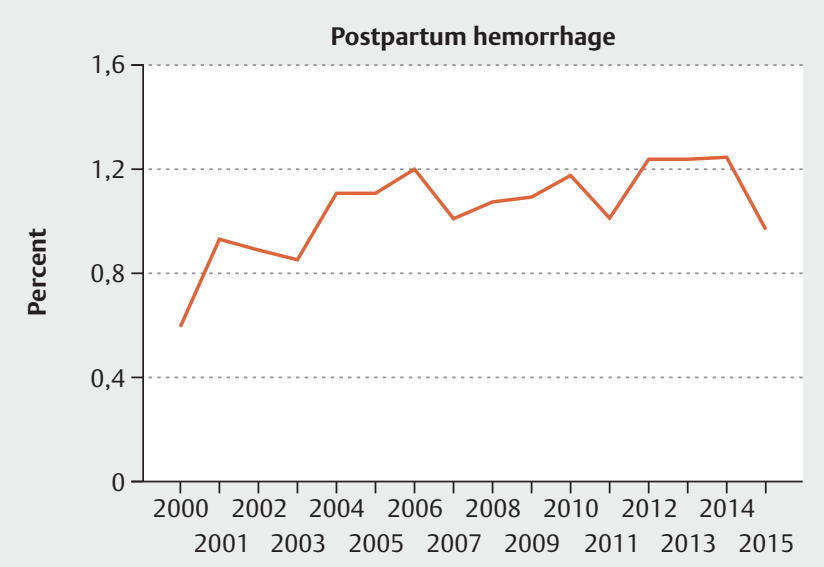

d

\section{Year}

Total

$455883798336395343043455434893 \quad 34543 \quad 37196$ 4004136278353993516834037338863640936959

Cases

- Fig. 3 Changes in the rates of cesarean sections and postpartum hemorrhage between 2000 and 2015. Total = total singleton deliveries $(n=583633)$, cases $=$ absolute incidence of specific outcome, $+=$ positive correlation, $-=$ negative correlation. All statistical analyses were carried out using logistic regression. a Total cesarean sections (\%): $n=178764, p<0.001(+)$. b Secondary cesarean sections (\%) $n=78719, p<0.001(+)$,

${ }^{*}$ data from 2007 was excluded due to missing values. c Emergency cesarean sections (\%): $\mathrm{n}=6397, \mathrm{p}<0.0001(-)$ (no data available in 2000 ).

d Postpartum hemorrhage $>1000 \mathrm{ml}(\%): \mathrm{n}=6067, \mathrm{p}<0.001(+)$.

rate of women with a GWG which was higher than the IOM recommendations rose from 64.54 to $68.55 \%$ ( $\vee$ Fig. 2 b, p $<0.001$ ).

However, there was no increase in the rate of HDP during the observation period ( $\boldsymbol{\vee}$ Fig. $\mathbf{2}$ d). $\mathbf{\nabla}$ Fig. $\mathbf{3}$ shows the increasing rates for total and secondary cesarean delivery, which rose from 22.79 to $33.2 \%$ and from $11.67 \%$ to $17.06 \%$. The postpartum hemorrhage (PPH) rate rose from $0.61 \%$ to $0.98 \%$ (both $p<0.001$ ). The rate of emergency cesarean deliveries decreased from $4.38 \%$ in 2000 to $3.56 \%$ in 2015 ( $p<0.0001)$.

In contrast to the declining rates of late preterm deliveries between $34+0$ and $36+6$ weeks $(p<0.001)$, the percentage of early preterm births $<28$ weeks $(p=0.26)$ and of deliveries between $28+0-33+6$ weeks of gestation $(p=0.12)$ did not change significantly ( $\bullet$ Fig. 4 a). 

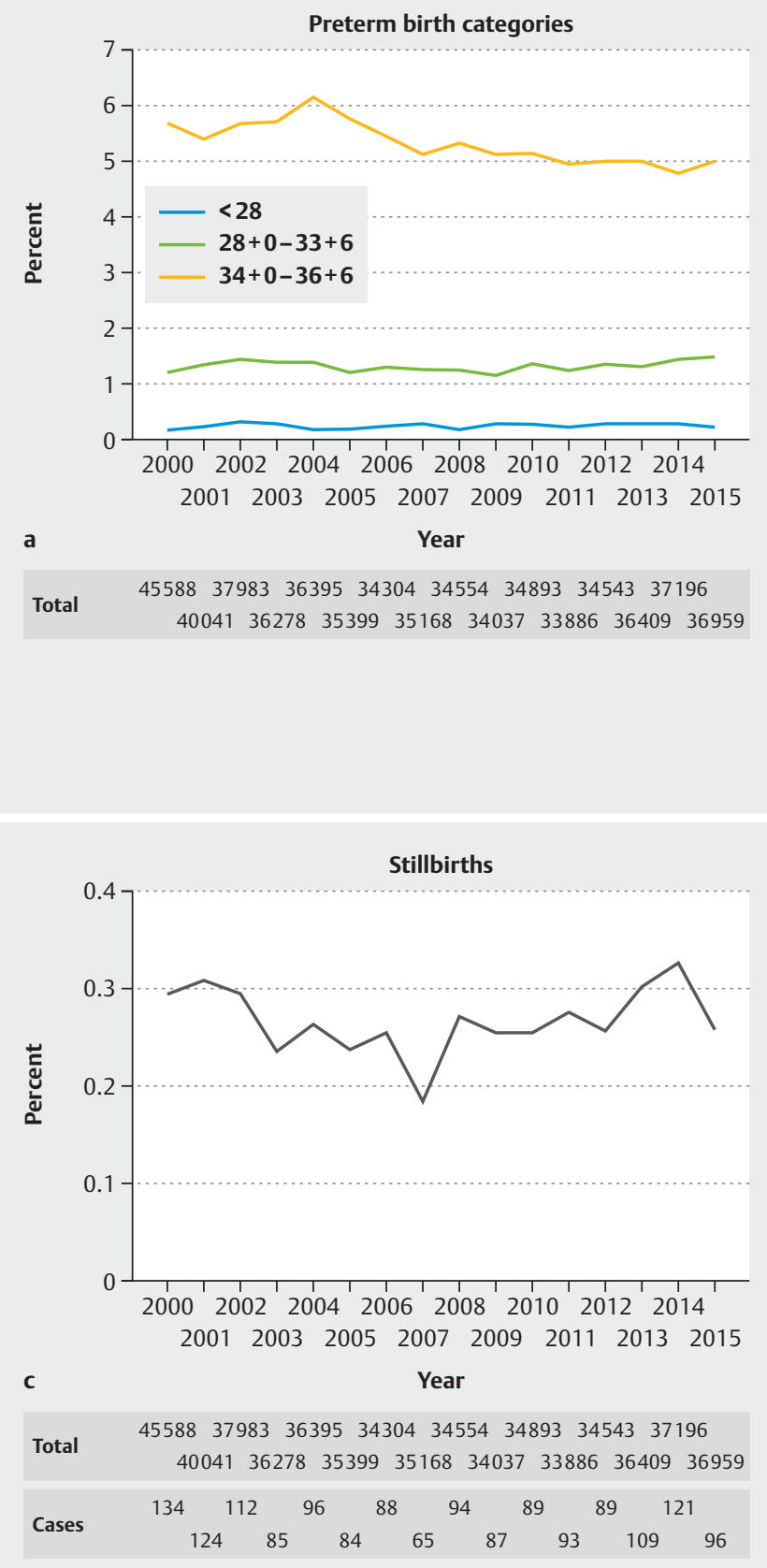

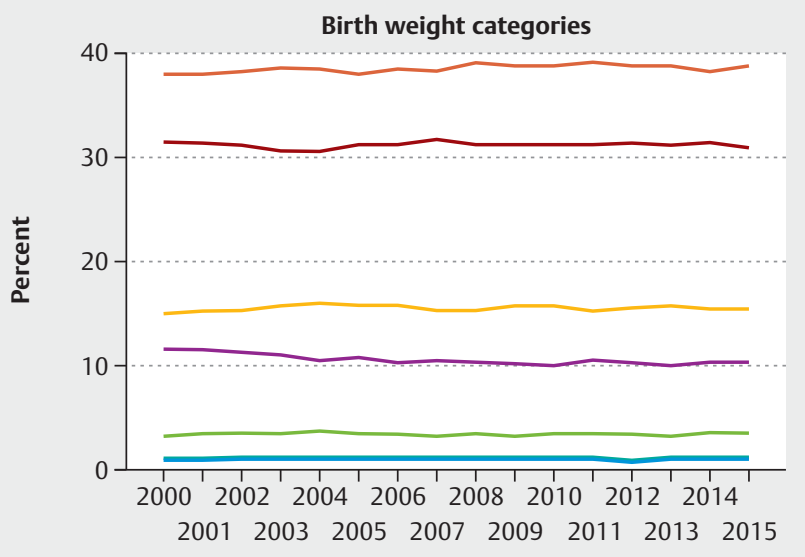

b

Year

Total

$45578 \quad 3761536393 \quad 34302 \quad 34546 \quad 34882 \quad 34542 \quad 37196$ $397383595035397 \quad 35164340273388536408 \quad 36957$
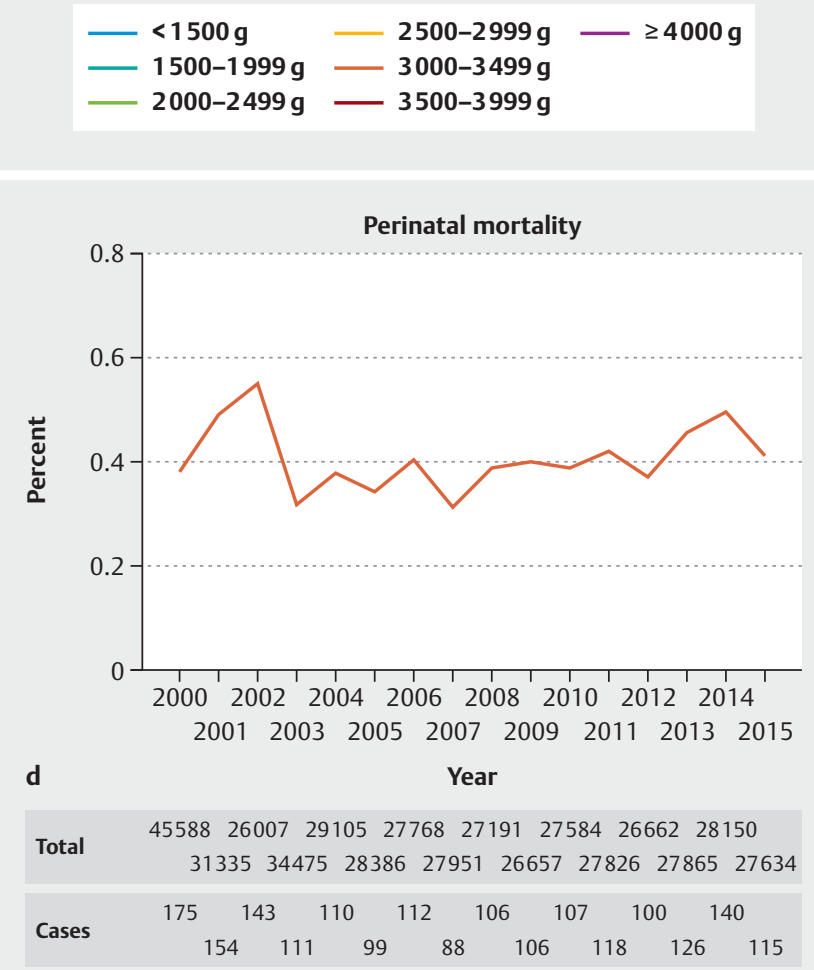

- Fig. 4 Course of neonatal outcomes (I) between 2000 and 2015. total = total singleton deliveries $(n=583633$ ), cases = absolute incidence of specific outcome, $+=$ positive correlation, $-=$ negative correlation. All statistical analyses were carried out using logistic regression. a Preterm deliveries (\%) according to category: delivery $<28$ weeks: $n=1732, p=0.26$; delivery between $28+0$ and $33+6$ weeks: $n=7990, p=0.12 ;$ delivery between $34+0$ and $36+6$ weeks: $n=31440, p<0.001(-)$. b Birth weight (\%) according to category: $<1500 \mathrm{~g}: \mathrm{n}=4825, \mathrm{p}<0.001(+) ; 1500-$ $1999 \mathrm{~g}: \mathrm{n}=5127, \mathrm{p}=0.07 ; 2000-2499 \mathrm{~g}: \mathrm{n}=18710, \mathrm{p}=0.37 ; 2500-2999 \mathrm{~g}: \mathrm{n}=89097, \mathrm{p}=0.07 ; 3000-3499 \mathrm{~g}: \mathrm{n}=223092, \mathrm{p}<0.001(+) ; 3500-$ $3999 \mathrm{~g}: \mathrm{n}=180765, \mathrm{p}=0.66 ; \geq 4000 \mathrm{~g}: \mathrm{n}=60964, \mathrm{p}<0.001$ (-). c Stillbirths (\%): $\mathrm{n}=1566, p=0.92$. $d$ Perinatal mortality $(\%): n=1910, p=0.53$.

The mean birth weight decreased from $3388 \mathrm{~g}$ in 2000 to $3362 \mathrm{~g}$ in $2015(\mathrm{p}<0.001)$. Accordingly, the course over time showed a higher incidence of newborns with a BW $<1500 \mathrm{~g}$ and a lower rate of macrosomic newborns ( $\geq 4000 \mathrm{~g},>$ Fig. 4 b). There was no significant change in the rates of stillbirth $(p=0.92)$ or perinatal mortality $(p=0.53)$ ( $\vee$ Fig. $4 c$ and $\mathbf{d})$, but there was an increase in the rate of poor immediate neonatal outcome (defined as an Apgar score of $<7$ at 5 minutes or an umbilical artery $\mathrm{pH}$ of $<7.1$ or both) ( $\vee$ Fig. $\mathbf{5}$ b to $\mathbf{d}, \mathrm{p}<0.01$ ). NICU admission rates increased from $7.77 \%$ in 2000 to $9.48 \%$ in 2015 ( $\mathbf{F i g . 5 a}$, $\mathrm{p}<0.0001)$. 


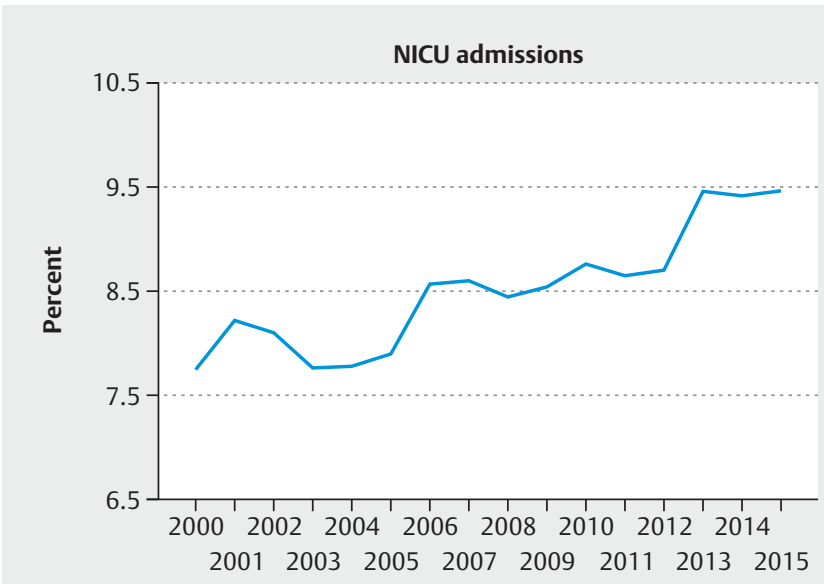

a
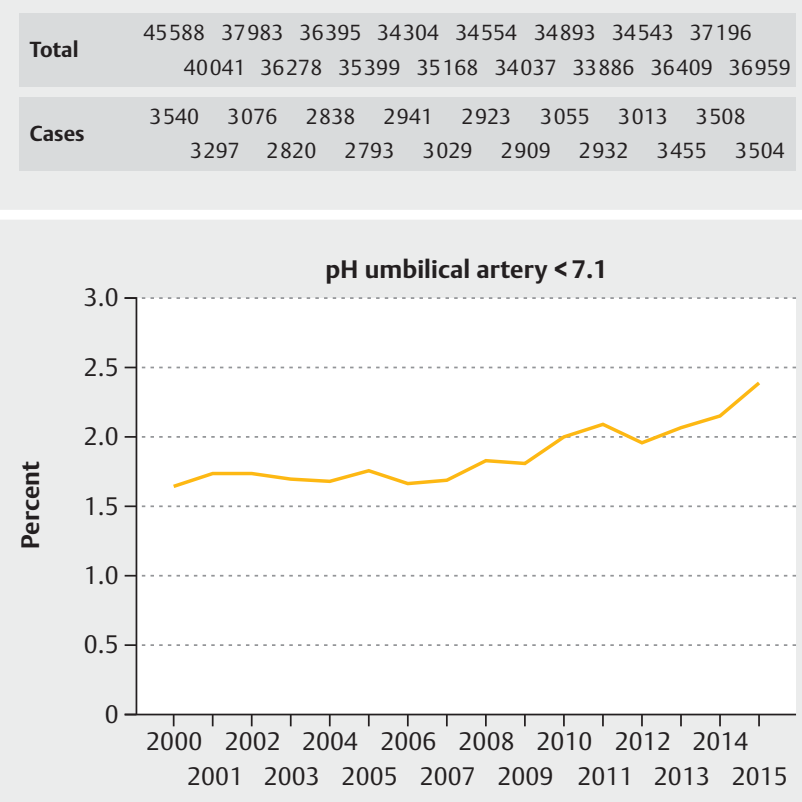

c

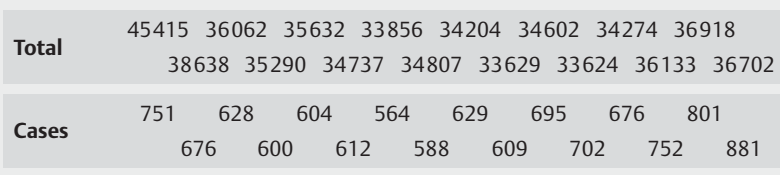

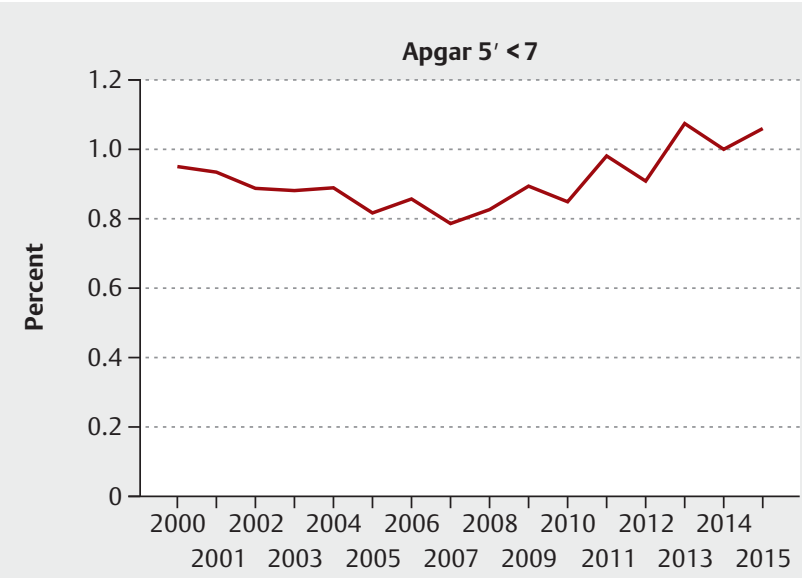

b

Year

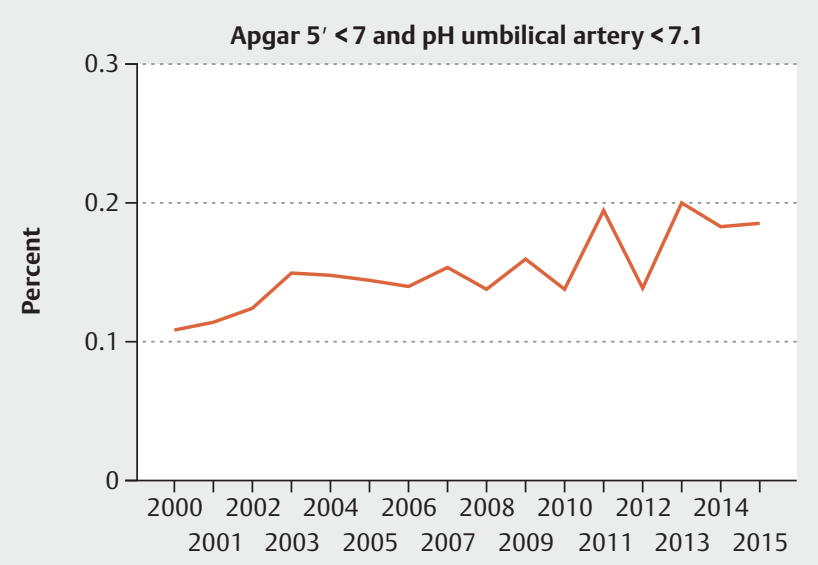

d

Year

Total

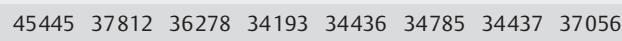

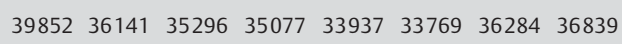

Cases

- Fig. 5 Course of neonatal outcomes (II) between 2000 and 2015. total = total singleton deliveries $(\mathrm{n}=583633)$, cases = absolute incidence of specific outcome, $+=$ positive correlation, $-=$ negative correlation. All statistical analyses were done using logistic regression. a NICU admissions (\%): $n=49633, p<0.0001(+)$. b Newborns with an Apgar score of less than 7 at 5 minutes (\%): $n=5342, p<0.01(+)$. c Newborns with an umbilical artery pH below $7.1(\%): n=10768, p<0.001(+)$. $\mathbf{d}$ Newborns with an Apgar score of less than 7 at 5 minutes and an umbilical artery pH of less than $7.1(\%): n=877, p<0.001(+)$.

\section{Discussion}

In this cohort study, the mean maternal age increased from 29.9 to 31.28 years between 2000 and 2015, which amounts to a rise of $4.7 \%$. Simultaneously, there was a $3 \%$ increase in mean maternal body weight and BMI and a $2.7 \%$ rise in maternal GWG. The rate of cesarean sections rose from $22.79 \%$ in 2000 to $33.20 \%$ in 2015. A parallel significant increase was observed for the rates of
$\mathrm{PPH}$, immediate poor neonatal outcome, and NICU admissions. The overall increase in HDP rates from $2.15 \%$ in 2000 to $2.55 \%$ in 2015 was not significant, because the rates between 2001 and 2003 were even higher.

Our results showing increasing maternal age, increased maternal BMI and increased cesarean section rates do not differ from global trends. However, the parallel increase in the rates of poor 
immediate maternal and neonatal outcomes has not been previously shown in a population-based study.

Increasing maternal age is observed in many Western countries $[17,18]$. In the USA, the percentage of births in women aged $\geq 30$ increased 2-fold; it increased 3-fold in women aged $\geq 35$ and nearly 4 -fold in women aged $\geq 40$. All of these changes occurred between 1980 and 2004 [19]. Older maternal age is a risk factor for prolonged and dysfunctional labor, $\mathrm{PPH}$, malpresentation, and primary cesarean delivery [19].

The increases in maternal overweight, BMI, and maternal GWG are consistent with the alarming global trend of overweight and obesity $[2,20]$ and had already been shown previously for other German cohorts [21-23]. A systematic review, published in 2017, stated that both low and high maternal pre-pregnancy BMI increases the risk of maternal morbidity and mortality [24]. Only one publication stated that severe maternal morbidity was not associated with pre-pregnancy obesity [25]. High maternal BMI is also associated with an increased risk of stillbirth, perinatal mortality, and infant death before the age of one year [26]. The risk of other immediate adverse maternal and infant outcomes such as preeclampsia, HDP, GDM, preterm birth, and small or large size for gestational age at birth also increases with a higher maternal BMI. Women with both a high BMI and EGWG are most at risk for these adverse outcomes [27]. Meanwhile, overweight and obesity are responsible for more global deaths than underweight and are a huge financial burden on our healthcare system [2]. Overweight and obesity are risk factors for reduced fertility, cardiovascular, renal, gastrointestinal, musculoskeletal and pulmonary diseases, and type II diabetes [28-30]. What was especially alarming was that in our cohort, $67 \%$ of women had EGWG above the recommendations of the IOM during pregnancy.

In 2010, cesarean delivery rates already varied considerably across Europe, ranging from $14.3 \%$ in Iceland to $49.9 \%$ in Cyprus [31]. In Central Europe, the rates were $16.1 \%$ in the Netherlands, $19.9 \%$ in France and 29.9\% in Germany [31]. Based on data from 121 countries, a trend analysis showed that between 1990 and 2014 , the global average rate of cesarean sections increased by $12.4 \%$, rising from 6.7 to $19.1 \%$, while the European rate increased by $3.8 \%$, from 11.2 to $15 \%$ [32]. Compared with other European countries, Germany has one of the highest cesarean delivery rates in Europe [33].

In our cohort, we observed an increase in overweight and obesity, as well as in the rate of EGWG. Although both are described as a risk factor for a cesarean delivery [34-36], the differences in cesarean delivery rates across Europe are not due to different levels of obesity but rather to differences in the quality of obstetric training, the general attitude of obstetricians and their incentives, and, last but not least, the malpractice policies in individual countries [37].

The increased rate of postpartum hemorrhage in our German cohort has also been observed in other Western countries [38], while global mortality from PPH has been steadily decreasing $[38,39]$. Antenatal risk factors for PPH include multiple pregnancy, anemia, macrosomia, placenta previa or increta, previous $\mathrm{PPH}$, as well as obesity and advanced maternal age [39]. The significant increase in maternal age, overweight, and obesity may have contributed to the rising rate of $\mathrm{PPH}$, but this does not pre- clude improving maternal surveillance post partum, particularly for "at-risk" patients, to prevent serious harm.

The increasing rate of NICU admissions observed in our cohort, which rose from 7.7 to $9.48 \%$, was also detected in the USA during a 6-year study period [40]. Increasing rates of cesarean sections as well as poor immediate neonatal outcomes as outlined above may be the reasons for this trend.

With regard to long-term outcomes, a study from Shanghai found an association between cesarean section and a higher risk of becoming overweight or obese in primary school children [41]. Excessive GWG is associated with long-term adverse maternal outcomes such as postpartum weight retention [42] and thus a higher risk in subsequent pregnancies. Being overweight or obese during pregnancy also has a negative impact on offspring, increasing their likelihood of being overweight or obese [43] even in adulthood, increasing their risk of being admitted for cardiovascular disease, and even increasing their risk of dying earlier compared to children born to women with a normal BMI [5].

A major strength of this study is the large cohort size, which permitted significant changes occurring in singleton pregnancies over a period of 15 years to be determined.

However, our study has also limitations. The database did not allow us to precisely determine the incidence of GDM, either because data were not provided or because it was unclear what the diagnosis was based on. The frequency of HDP could only be calculated indirectly from the clinical findings (blood pressure, proteinuria). Calculated to be only $2.7 \%$, the mean rate of HDP in our cohort is therefore smaller than the suggested prevalence of 5.2 to $8.2 \%$ reported in other studies [44].

Another limitation of our study is that we used the BMI documented at the first visit (before 14 weeks of gestation) rather than the pre-pregnancy BMI, which is rarely available to the obstetrician. It is debatable whether recalled weight prior to pregnancy would be more reliable than the weight measured objectively at an early stage in pregnancy. Since the GWG in the first trimester is only about $0.5-2 \mathrm{~kg}$ according to the IOM [12], the difference is likely to be negligible.

As the study was based on anonymous unlinked data, it was not possible to identify mothers who had more than one pregnancy during the observation period. The problem that there was no plausibility control of the data when it was entered in the database was compensated by a one-year full-time retrospective plausibility control by our group, which also resulted in an increase in "missing values" when we found non-plausible data.

\section{Conclusion}

In the present paper, we have demonstrated that increasing rates of maternal overweight and obesity and simultaneously increasing rates of excessive gestational weight gain are also present in German cohorts and are accompanied by increasing rates of HDP and cesarean delivery, with no improvements in neonatal outcomes. The risk factors for pre-pregnancy overweight and obesity as well as for insufficient or excessive weight gain during pregnancy and an analysis of how these associations could be the cause of poor maternal and neonatal outcomes is a subject for future investigations. We investigated the impact of pre-pregnancy 
BMI, as defined by the criteria of the WHO, on maternal and neonatal outcomes using univariate linear regression for continuous variables and multivariate regression analysis for categorical and numerical variables with many predefined confounders.

Our present results already point to alarming consequences for women and their offspring due to irreversible epigenetic mechanisms which are insufficiently communicated to women at risk. Midwives and obstetricians are ideally positioned to initiate algorithms before and after pregnancy which could interrupt the vicious circle of transgenerational consequences. Widespread education of patients and healthcare providers is required to identify and treat the modifiable intergenerational risks of obesity and the associated metabolic, cardiovascular and mental diseases for the benefit of future generations.

\section{Acknowledgements}

The authors would like to thank Dr. med Björn Misselwitz and the "Geschäftsstelle Qualitätssicherung Hessen” for their support in the acquisition of data.

Conflict of Interest

The authors declare that they have no conflict of interest.

\section{References}

[1] Sepúlveda J, Murray C. The state of global health in 2014. Science 2014; 345: 1275-1278. doi:10.1126/science. 1257099

[2] WHO. Obesity and overweight. Online: https://www.who.int/news-room /fact-sheets/detail/obesity-and-overweight; last access: 07.06.2019

[3] Poston L, Caleyachetty R, Cnattingius S et al. Preconceptional and maternal obesity: epidemiology and health consequences. Lancet Diabetes Endocrinol 2016; 4: 1025-1036. doi:10.1016/S2213-8587(16)30217-0

[4] Arabin B, Stupin JH. Overweight and Obesity before, during and after Pregnancy: Part 2: Evidence-based Risk Factors and Interventions. Geburtsh Frauenheilk 2014; 74: 646-655. doi:10.1055/s-0034-1368462

[5] Reynolds RM, Allan KM, Raja EA et al. Maternal obesity during pregnancy and premature mortality from cardiovascular event in adult offspring: follow-up of 1323275 person years. BMJ 2013; 347: f4539. doi:10.1136/ bmj.f4539

[6] Stupin JH, Arabin B. Overweight and Obesity before, during and after Pregnancy: Part 1: Pathophysiology, Molecular Biology and Epigenetic Consequences. Geburtsh Frauenheilk 2014; 74: 639-645. doi:10.1055/ s-0034-1368486

[7] Arabin B, Timmesfeld N, Noever $\mathrm{K}$ et al. How to improve health literacy to reduce short- and long-term consequences of maternal obesity? J Matern Fetal Neonatal Med 2019; 32: 2935-2942. doi:10.1080/ 14767058.2018.1450383

[8] Arabin B, Timmesfeld N, Noever $\mathrm{K}$ et al. Adipositas-Prävention. Frauen frühzeitig erreichen. Deutsche Hebammen Zeitschrift 2018; 70: 66-70

[9] Arabin B, Stupin JH. Übergewicht und Adipositas: Risiken und Interventionen. Die Hebamme 2016; 29: 47-54. doi:10.1055/s-0042-100782

[10] [Anonymous]. ACOG Committee opinion no. 549: obesity in pregnancy. Obstet Gynecol 2013; 121: 213-217. doi:10.1097/01.AOG.0000425667. 10377.60

[11] [Anonymous]. ACOG Practice Bulletin No 156: Obesity in Pregnancy. Obstet Gynecol 2015; 126: e112-e126. doi:10.1097/AOG.0000000000 001211
[12] Rasmussen KM, Yaktine AL, eds. Weight Gain during Pregnancy: Reexamining the Guidelines. Washington (DC): The National Academies Press; 2009. doi:10.17226/12584

[13] Gesell SB, Katula JA, Strickland C et al. Feasibility and Initial Efficacy Evaluation of a Community-Based Cognitive-Behavioral Lifestyle Intervention to Prevent Excessive Weight Gain During Pregnancy in Latina Women. Matern Child Health J 2015; 19: 1842-1852. doi:10.1007/s10995015-1698-x

[14] Hessisches Statistisches Landesamt. Tabellen Bevölkerung (15.06.2019). Online: https://statistik.hessen.de/zahlen-fakten/bevoelkerung-gebiethaushalte-familien/bevoelkerung/tabellen; last access: 15.06.2019

[15] World Health Organization (WHO). What is overweight and obesity? Online: https://www.who.int/dietphysicalactivity/childhood_what/en/; last access: 30.06.2019

[16] Brown MA, Magee LA, Kenny LC et al. Hypertensive Disorders of Pregnancy: ISSHP Classification, Diagnosis, and Management Recommendations for International Practice. Hypertension 2018; 72: 24-43. doi:10.1161/HYPERTENSIONAHA.117.10803

[17] Eurostat. Fakten - Durchschnittliches Alter der Mütter bei Geburt ihrer Kinder (in Jahren) in europäischen Ländern, 1960 bis 2016. Online: https://www.bib.bund.de/DE/Fakten/Fakt/F53-Alter-Muetter-beiGeburt-Europa-ab-1960.html;jsessionid=856CCD869BCEBEC61B6A6E0 64E7E4035.2_cid389?nn=9754814; last access: 14.08 .2019

[18] Mathews T], Hamilton BE. Mean Age of Mothers is on the Rise: United States, 2000-2014. NCHS Data Brief 2016; (232): 1-8

[19] Luke B, Brown MB. Elevated risks of pregnancy complications and adverse outcomes with increasing maternal age. Hum Reprod 2007; 22: 1264-1272. doi:10.1093/humrep/del522

[20] Statistisches Bundesamt. Body Mass Index BMI der erwachsenen Bevölkerung [Stichwort: BMI] (14.08.2019). Online: http://www.gbe-bund. de/gbe10/abrechnung.prc_abr_test_logon?p_uid=gast\&p_aid=0 \&p_knoten=FID\&p_sprache=D\&p_suchstring=8397::BMI\#tab3; last ac cess: 14.08 .2019

[21] Bergmann KE, Bergmann RL, Ellert U et al. Perinatale Einflussfaktoren auf die spätere Gesundheit. Ergebnisse des Kinder- und Jugendgesundheitssurveys (KiGGS). Bundesgesundheitsblatt Gesundheitsforschung Gesundheitsschutz 2007; 50: 670-676. doi:10.1007/s00103-007-0228-4

[22] Ferrari N, Mallmann P, Brockmeier K et al. Secular trends in pregnancy weight gain in German women and their influences on foetal outcome: a hospital-based study. BMC Pregnancy Childbirth 2014; 14: 228. doi:10.1186/1471-2393-14-228

[23] Voigt M, Straube S, Zygmunt $M$ et al. Obesity and pregnancy-a risk profile. Z Geburtshilfe Neonatol 2008; 212: 201-205. doi:10.1055/s-20081076995

[24] Lisonkova S, Muraca GM, Potts J et al. Association Between Prepregnancy Body Mass Index and Severe Maternal Morbidity. JAMA 2017; 318: 1777-1786. doi:10.1001/jama.2017.16191

[25] Leonard SA, Main EK, Carmichael SL. The contribution of maternal characteristics and cesarean delivery to an increasing trend of severe maternal morbidity. BMC Pregnancy Childbirth 2019; 19: 16. doi:10.1186/ s12884-018-2169-3

[26] Aune D, Saugstad OD, Henriksen T et al. Maternal body mass index and the risk of fetal death, stillbirth, and infant death: a systematic review and meta-analysis. JAMA 2014; 311: 1536-1546. doi:10.1001/jama. 2014.2269

[27] Voerman E, Santos S, Inskip H et al. Association of Gestational Weight Gain With Adverse Maternal and Infant Outcomes. JAMA 2019; 321: 1702-1715. doi:10.1001/jama.2019.3820

[28] Zheng W, McLerran DF, Rolland B et al. Association between body-mass index and risk of death in more than 1 million Asians. N Engl J Med 2011; 364: 719-729. doi:10.1056/NEJMoa1010679 
[29] Whitlock G, Lewington S, Sherliker P et al.; Prospective Studies Collaboration. Body-mass index and cause-specific mortality in 900000 adults: collaborative analyses of 57 prospective studies. Lancet 2009; 373: 1083-1096. doi:10.1016/S0140-6736(09)60318-4

[30] Lu Y, Hajifathalian K, Ezzati M et al.; Global Burden of Metabolic Risk Factors for Chronic Diseases Collaboration (BMI Mediated Effects). Metabolic mediators of the effects of body-mass index, overweight, and obesity on coronary heart disease and stroke: a pooled analysis of 97 prospective cohorts with 1.8 million participants. Lancet 2014; 383: 970-983. doi:10.1016/S0140-6736(13)61836-X

[31] Macfarlane A], Blondel B, Mohangoo AD et al. Wide differences in mode of delivery within Europe: risk-stratified analyses of aggregated routine data from the Euro-Peristat study. BJOG 2016; 123: 559-568. doi:10.1111/1471-0528.13284

[32] Betrán AP, Ye J, Moller AB et al. The Increasing Trend in Caesarean Section Rates: Global, Regional and National Estimates: 1990-2014. PLoS One 2016; 11: e0148343. doi:10.1371/journal.pone.0148343

[33] OECD. Caesarean sections (indicator). 2020. doi:10.1787/adc3c39f-en. Online: https://data.oecd.org/pinboard/4j3z; last access: 06.03.2020

[34] Goldstein RF, Abell SK, Ranasinha S et al. Association of Gestational Weight Gain With Maternal and Infant Outcomes: A Systematic Review and Meta-analysis. JAMA 2017; 317: 2207-2225. doi:10.1001/jama. 2017.3635

[35] Goldstein RF, Abell SK, Ranasinha S et al. Gestational weight gain across continents and ethnicity: systematic review and meta-analysis of maternal and infant outcomes in more than one million women. BMC Med 2018; 16: 153. doi:10.1186/s12916-018-1128-1

[36] Ferrazzi E, Brembilla G, Cipriani S et al. Maternal age and body mass index at term: Risk factors for requiring an induced labour for a late-term pregnancy. Eur J Obstet Gynecol Reprod Biol 2019; 233: 151-157. doi:10.1016/j.ejogrb.2018.12.018
[37] Schwarz C. Dem Wahnsinn Einhalt gebieten? - Die aktuelle US-amerikanische Leitlinie zur Senkung der Kaiserschnittrate. Die Hebamme 2014; 27: 84-90. doi:10.1055/s-0034-1373858

[38] Knight M, Callaghan WM, Berg C et al. Trends in postpartum hemorrhage in high resource countries: a review and recommendations from the International Postpartum Hemorrhage Collaborative Group. BMC Pregnancy Childbirth 2009; 9: 1-10. doi:10.1186/1471-2393-9-55

[39] Weeks A. The prevention and treatment of postpartum haemorrhage: what do we know, and where do we go to next? BJOG 2015; 122: 202210. doi:10.1111/1471-0528.13098

[40] Harrison W, Goodman D. Epidemiologic Trends in Neonatal Intensive Care, 2007-2012. JAMA Pediatr 2015; 169: 855-862. doi:10.1001/ jamapediatrics.2015.1305

[41] Chu S, Zhang Y, jiang $Y$ et al. Cesarean section and risks of overweight and obesity in school-aged children: a population-based study. QJM 2018; 111: 859-865. doi:10.1093/qjmed/hcy195

[42] Nehring I, Schmoll S, Beyerlein A et al. Gestational weight gain and longterm postpartum weight retention: a meta-analysis. Am J Clin Nutr 2011; 94: 1225-1231. doi:10.3945/ajcn.111.015289

[43] Houghton LC, Ester WA, Lumey LH et al. Maternal weight gain in excess of pregnancy guidelines is related to daughters being overweight 40 years later. Am J Obstet Gynecol 2016; 215: 246.e1-246.e8. doi:10.1016/j.ajog.2016.02.034

[44] Umesawa M, Kobashi G. Epidemiology of hypertensive disorders in pregnancy: prevalence, risk factors, predictors and prognosis. Hypertens Res 2017; 40: 213-220. doi:10.1038/hr.2016.126 